\title{
Rapid Resolution of Traumatic Pneumatocyst in the Cervical Spine: A Case Report
}

\author{
Jae Hoo Park', Seok Won Kim ${ }^{1}$, Hyeun Sung Kim ${ }^{3}$, Jae Ung Ko ${ }^{2}$ \\ Departments of ${ }^{I}$ Neurosurgery, ${ }^{2}$ Ophthalmology, Chosun University College of Medicine, Gwangju, \\ ${ }^{3}$ Department of Neurosurgery, Sun Han Hospital, Gwangju, Korea
}

Intraosseous pneumatocyst is a benign, gas-filled, cystic lesion, and is commonly encountered in iliac bone or sacrum. Other locations of this lesion following trauma are rare, and only a handful of isolated cases have been reported. The pathogenesis and etiologies of this uncommon entity are various and it can present a diagnostic challenge. Only four previous cases have described the natural course of intravertebral pneumatocysts. Here, the authors report a rare case of traumatic pneumatocyst, which resolved rapidly without further complication. Possible pathogenic mechanisms are discussed and reviews of literatures are included.

Key Words: Pneumatocyst • Cervical · Trauma

\section{INTRODUCTION}

Intraosseous gas collection is observed in various pathologic conditions, including osteomyelitis by gas-forming organisms, vertebral collapse due to osteonecrosis, neoplasms, and posttraumatic conditions ${ }^{2,3,11)}$. Intraosseous pneumatocysts are frequently observed in the ilium or sacrum adjacent to the sacroiliac joint. However, intraosseous pneumatocysts, involving a gas-filled cystic lesion of uncertain origin in bone, are relatively rare, and traumatic pneumatocysts in the cervical spine are extremely rare ${ }^{3,4)}$. In fact, only four cases have described the natural course of this rare entity, which remains unclear, ${ }^{6,8,10)}$.

Here, we report a unique case of traumatic pneumatocyst in the cervical spine that exhibited spontaneous, rapid resolution, and include reviews of literatures.

\section{CASE REPORT}

A 54-year-old man with severe neck pain was referred to

- Received: April 9, 2015 • Revised: May 21, 2015

- Accepted: June 21, 2015

Corresponding Author: Seok Won Kim, MD, PhD

Department of Neurosurgery, Chosun University College of Medicine,

365 Pilmun-daero, Dong-gu, Gwangju-city 501-717, Korea

Tel: +82-62-220-3126, Fax: +82-62-227-4575

E-mail: ns64902@hanmail.net/chosunns@chosun.ac.kr

అThis is an Open Access article distributed under the terms of the Creative Commons Attribution Non-Commercial License (http://creativecommons.org/ licenses/by-nc/3.0/) which permits unrestricted non-commercial use, distribution, and reproduction in any medium, provided the original work is properly cited. our emergency room following a high-speed motorcycle accident. The patient had no previous history of anticoagulant therapy or hematological coagulopathy, and was in good health before this episode. On physical examination, he was alert and fully oriented. No neurologic abnormalities were found for cranial nerves or the cerebellar system. Brain computed tomography (CT) revealed no evidence of any abnormality. However, lamina fractures of $\mathrm{C} 6$ and $\mathrm{C} 7$ and an irregular lesion of around $10 \times 10 \times 10 \mathrm{~mm}$ filled with gas in the $\mathrm{C} 6$ vertebral body were visualized by CT (Fig. 1). The lesion did not communicate with the spinal canal or intervertebral disc. Conservative treatment including bed rest, $\mathrm{O}_{2}$ inhalation, and medication for pain relief was administered. A follow-up CT scan taken 3 days after injury revealed that the intravertebral gas had completely resolved with no further complication (Fig. 2). The patient remained in good health and was free of neurological deficits during the 3-month follow-up period.
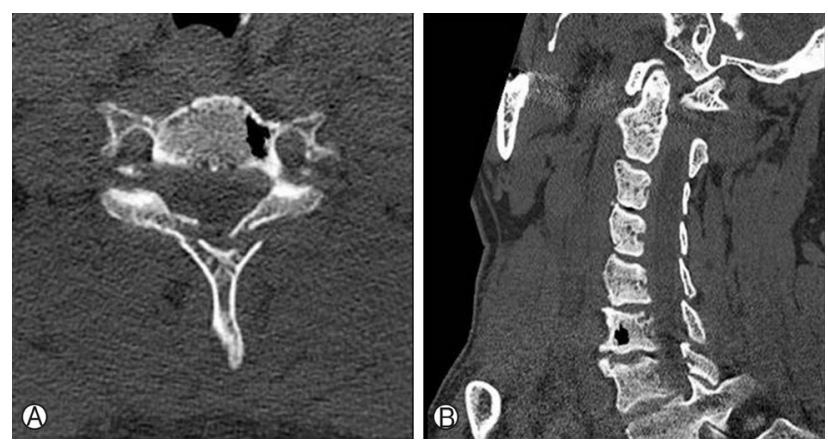

Fig. 1. (A \& B) Initial computed tomography scans show gas attenuation in the $\mathrm{C} 6$ body. 
Table 1. Summary of previously reported intravertebral pneumatocysts and their natural courses

\begin{tabular}{lcccccl}
\hline \hline Author & Reference & Age/Sex & Level & Cause & Follow-up period & Natural Course \\
\hline Kitagawa et al. & 4 & $69 / \mathrm{M}$ & C5 & Degenerative & 16 months & Enlarging \\
Nakayama et al. & 7 & $56 / \mathrm{M}$ & L5 & Degenerative & 16 months & Fluid cyst \\
& 9 & $57 / \mathrm{M}$ & C5 & Degenerative & 2 months & Fluid cyst \\
Yamamoto et al. & 9 & $56 / \mathrm{M}$ & C5 & Degenerative & 40 weeks & Granulation tissue \\
Present Case & - & $54 / \mathrm{M}$ & C6 & Trauma & 3 months & Spontaneous regression \\
\hline
\end{tabular}
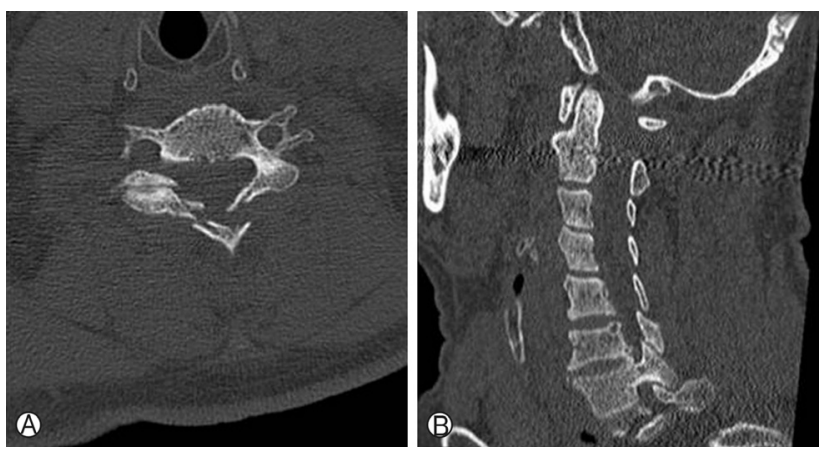

Fig. 2. (A \& B) Follow-up computed tomography scans 3 days after admission reveal complete resolution of the gas.

\section{DISCUSSION}

Intraosseous pneumatocyst is a rare condition in which a gas-filled cystic lesion of uncertain origin occupies bone ${ }^{2)}$. However, they are rarely detected in vertebral bodies, and to our knowledge, only few cases have been reported in the body of cervical vertebrae, and most of these cases occurred in the setting of spondylosis (Table 1) ${ }^{5-7,9)}$. Although percutaneous injection of bone graft substitute material for treatment of a symptomatic pneumatocysts was reported as a treatment option, they are nearly always treated conservatively ${ }^{1}$. Several authors have stated that the sizes of pneumatocysts remain stable based on radiological examinations. However, Nakayama et al. ${ }^{8)}$ reported two pneumatocysts, one in the cervical spine and the other in the lumbar spine, that spontaneously progressed to fluidfilled cysts, 6-16 months after initial presentation. Yamamoto et al. ${ }^{10)}$ reported a cervical pneumatocyst that changed to a fluid-filled cyst and that was subsequently replaced by granulation tissue, as shown by magnetic resonance imaging at 40weeks, and Kitagawa et al. ${ }^{6}$ reported the first enlarging pneumatocyst as determined by 16-month follow-up. To the best of our knowledge, our case of a traumatic pneumatocyst in the $\mathrm{C} 6$ vertebral body is the first to shown rapid resolution by 3 day follow-up CT. Although the etiology of cervical pneumatocyst is unclear, except for those associated with pathological conditions, a number of authors have hypothesized about its origins and natural courses. The gas inside a pneumatocyst is primarily nitrogen, and some authors have suggested that negative pressure within the lesion (due to some unknown mechanism) causes the release of nitrogen from surrounding soft tissues or articular joints ${ }^{8,9}$. Gas in degenerated intervertebral discs, known as the "vacuum phenomenon", is often observed in the degenerated spine, and extension of gas from an intervertebral disc into a vertebral body through a defect in a degenerated endplate could possibly cause an intravertebral pneumatocyst ${ }^{9}$. Furthermore, the radiolucent and osteolytic images of pneumatocysts in plain radiographs may mimic metastatic lesions. CT is the most useful radiological tool for the correct diagnosis of pneumatocysts, which exhibit no contrast enhancement on CT images. Traumatic intravertebral pneumatocysts are benign innocuous lesions that need to be differentiated from other gas-containing lesions of the spine, including those caused by osteomyelitis, osteonecrosis, or neoplasms.

\section{CONCLUSION}

Traumatic cervical pneumatocyst is a rare benign lesion that requires no specific treatment. Neurosurgeons should note that this condition could resolve rapidly and spontaneously without complications.

\section{ACKNOWLEDGMENT}

This study was supported by research funds from Chosun University Great 2015.

\section{REFERENCES}

1. Formby PM, Kang DG, Potter BK, Forsberg JA: Treatment of symptomatic intraosseous pneumatocyst using intraoperative navigation. Orthopedics 38:244-247, 2015

2. Grunshaw ND, Carey BM: Case report: gas within a cervical vertebral body. Clin Radiol 49:653-654, 1994

3. Hall FM, Turkel D: Case report 536: Intraosseous pneumocyst of the ilium. Skeletal Radiol 18:127-128, 1989

4. Karadick D, Eason MA: Vertebral pneumatocyst mimicking 
susceptibility artifact on MR imaging. AJR Am J Roentgenol 170:221, 1998

6. Kim $\mathrm{CH}$ : Pneumorrhachis and paraspinal air with vacumn disc: case report and literature review. J Korean Neurosurg Soc 42: 490-491, 2007

6. Kitagawa T, Fujiwara A, Tamai K, Kobayashi N, Saiki K, Omata $\mathrm{S}$, et al: Enlarging vertebral body pneumatocysts in the cervical spine. AJNR 24:1707-1710, 2003

7. Larsen JL, Smievoll AI: Gas in a cervical vertebral body. A case report with CT confirmation. Eur J Radiol 8:98-99, 1988

8. Nakayama T, Ehara S, Hama H: Spontaneous progression of vertebral intraosseous pneumatocysts to fluid-filled cysts. Skeletal Radiol 30:523-526, 2001

9. Sunder S, Prasad R: Vertebral body pneumatocysts in the cervical spine - A case report. Apollo Medicine 5:121-124, 2008

10. Yamamoto T, Yoshiya S, Kurosaka M, Nagira K, Takabatake $\mathrm{M}$, Hamamoto $\mathrm{H}$, et al: Natural course of an intraosseous pneumatocyst of the cervical spine. AJR Am J Roentgenol 179:667669, 2002

11. Yun SM, Suh BS, Park JS: Symptomatic epidural gas-containing cyst from intervertebral vacuum phenomenon. Korean J Spine 9:365-368, 2012 